\title{
EL DERECHO DEL NIÑO A EMITIR OPINIÓN Y SU RELACIÓN CON LA ADOPCIÓN
}

María Isabel Sokolich Alva ${ }^{1}$

\begin{abstract}
RESUMEN
El respeto de la opinión del niño, niña y adolescente en todo procedimiento administrativo, proceso judicial, políticas públicas y en toda decisión que los involucre debe ser una premisa del Estado a fin de consolidar su rol de garante de los derechos humanos de este grupo poblacional especialmente vulnerable, el cual acorde al artículo $4 .^{\circ}$ de la Constitución Política del Estado merece especial protección. Los procedimientos administrativos de adopción no están exentos de observar, sin restricción alguna, el ejercicio de dicho derecho, el cual en forma acertada es exigido en diversas etapas de los procedimientos por riesgo y desprotección familiar regulados por el Decreto Legislativo N. ${ }^{\circ} 1297$.
\end{abstract}

\section{ABSTRACT}

Respect for the opinion of children and adolescents in all administrative proceedings, judicial process, public policies and in any decision that involves them must be a premise of the State in order to consolidate its role as guarantor of the human rights of this population group especially vulnerable, which according to Article No. 4 of the Political Constitution of the State deserves special protection. Administrative procedures for adoption are not exempt from observing, without restriction, the exercise of this right, which is properly required in various stages of the procedures for risk and family protection regulated by Legislative Decree No. 1297.

\section{PALABRAS CLAVE}

Opinión del niño. Interés superior del niño. Filiación. Adopción.

\section{KEY WORDS}

Child's opinion. Superior interest of the child. Filiation. Adoption

\section{EL DERECHO DEL NIÑO A EX- PRESAR SU OPINIÓN LIBRE- MENTE EN TODOS LOS ASUN- TOS QUE LO AFECTEN:}

El reconocimiento de la opinión del niño, niña y adolescente ${ }^{2}$ conjuntamente con el derecho a la vida, supervivencia y desarrollo, la no discriminación y la prevalencia de su interés superior constituyen principios fundamentales y base de la doctrina de la protección integral que esboza la Convención sobre los Derechos del Niño de 1989. En la línea del tiempo, dicho instrumento internacional de derechos humanos determina un antes $y$ un después en el tratamiento de los derechos de la infancia, en contraposición a la doctrina de la situación irregular.

\footnotetext{
Doctora en Derecho por la Universidad San Martín de Porres. Magíster en Derecho Civil con mención en Derecho de Familia por la Universidad Femenina del Sagrado Corazón. Fiscal Adjunto Supremo de la Fiscalía Suprema Civil. Docente de la Maestría de Derecho Civil con mención en Derecho de Familia de la Universidad Femenina del Sagrado Corazón -UNIFE-, así como de la Maestría de Derecho de Persona, Matrimonio y Familia de la Universidad Católica Santo Toribio de Mogrovejo. Docente de la Academia de la Magistratura en la especialidad de Derecho de Familia. Autora del libro "Violencia Familiar" y de diversos artículos jurídicos de la especialidad. Expositora en diversos eventos académicos relacionados con el Derecho de Familia.

2 En adelante siguiendo la pauta del artículo $1 .^{\circ}$ de la Convención sobre los Derechos del Niño nos referiremos a este grupo poblacional con las expresiones "niño” o “niños”, según corresponda.
} 
El artículo 9. ${ }^{\circ}$ del Código de los Niños y Adolescentes ${ }^{3}$ tiene como antecedente el artículo $12 .^{\circ}$ de la Convención ${ }^{4}$, el cual ha sido desarrollado ampliamente por el Comité de los Derechos del Niño por la Observación General N. 12, del 20 de julio de 2009, con el título "El derecho del niño a ser escuchado".

Dicha Observación General, examina los aspectos sustanciales del derecho del niño a emitir opinión desde un actividad hermenéutica e integradora de la propia Convención; así, se parte por señalar que este derecho tiene un doble matiz, pues, de un lado, implica el reconocimiento del derecho del niño a expresarse libre y voluntariamente en "todos" los asuntos en los que se encuentre inmerso; y, de otro, determina la obligación de los Estados de realizar en la práctica los derechos humanos de los niños, entre otros, teniendo en cuenta dicha opinión en función de la edad y madurez del niño.

Debemos resaltar, que los Estados en su calidad de garantes de los derechos humanos, más aún respecto de los instrumentos internacionales con los cuales están vinculados, tienen la obligación de respetar, proteger y realizar dichos derechos de forma real y concreta, lo cual exige políticas públicas, un marco normativo y una actuación diligente y oportuna por parte de las autoridades llamadas a asegurar la efectividad de dichos derechos. Este comportamiento en mayor grado corresponde ser asumido cuando de los derechos de los niños, niñas y adolescentes se trata, en atención a su mayor vulnerabilidad.

Ahora bien, en lo referido al ejercicio mismo del derecho a emitir opinión se enfatiza que el niño puede decidir no ejercitar este derecho, pues para aquel expresar sus opiniones es una opción más no una obligación, por ello es necesario que los Estados adopten las medidas necesarias para que el niño reciba en forma previa información y asesoría suficiente que le permitan decidir libremente el ejercicio de su derecho, lo cual no es otra cosa que el reconocimiento del niño como "sujeto de derechos".

Es decir, el niño ya no puede seguir siendo considerado como objeto de tutela, de tal forma, que son otros (padres, autoridad judicial o el propio Estado) quienes en su nombre y representación deciden en forma unilateral o arbitraria lo que a su consideración es "mejor" para él, sino, que corresponde al propio niño, previa información de los hechos, expresar, si así lo desea, su po- sición, parecer, sentir o querer respecto de un tema o aspecto que lo compromete.

Es importante tener en cuenta, que la Observación General ratifica que el artículo $12 .^{\circ}$ de la Convención no impone ningún límite de edad al derecho del niño a expresar su opinión, pues el niño desde la primera infancia e incluso no habiendo desarrollado lenguaje verbal, es capaz de formarse una opinión a partir de sus propias vivencias.

En casos como el planteado, la garantía del derecho del niño a emitir opinión es factible ser materializado a través de formas no verbales de comunicación, como el juego, expresión corporal y facial, dibujo, pintura u otros medios igualmente válidos.

Este aspecto es de vital importancia, pues en algunos casos, tanto en sede judicial como administrativa, se ha privado al "niño pequeño" del ejercicio de su derecho a opinar, bajo la excusa de que la corta edad del niño no le permitía percibir lo que acontecía en su vida cotidiana y menos expresarse oralmente.

En relación al tema, es importante reseñar que la Observación General N. ${ }^{\circ} 07$ del Comité de los Derechos del Niño (2006), concerniente a la

3 Artículo 9.- A la libertad de opinión.-

El niño y el adolescente que estuvieren en condiciones de formarse sus propios juicios tendrán derecho a expresar su opinión libremente en todos los asuntos que les afecten y por los medios que elijan, incluida la objeción de conciencia, y a que se tenga en cuenta sus opiniones en función de su edad y madurez.

4 Artículo 12

1. Los Estados Partes garantizarán al niño que esté en condiciones de formarse un juicio propio el derecho de expresar su opinión libremente en todos los asuntos que afectan al niño, teniéndose debidamente en cuenta las opiniones del niño, en función de la edad y madurez del niño.

2. Con tal fin, se dará en particular al niño oportunidad de ser escuchado, en todo procedimiento judicial o administrativo que afecte al niño, ya sea directamente o por medio de un representante o de un órgano apropiado, en consonancia con las normas de procedimiento de la ley nacional. 
"Realización de los Derechos del Niño en la Primera Infancia", es taxativa al señalar que los niños pequeños son beneficiarios de todos los derechos consagrados en la Convención, de tal forma que tienen derecho a medidas especiales de protección de conformidad a sus capacidades en evolución y al ejercicio progresivo de sus derechos.

Es así, que entre los objetivos planteados por dicha Observación se destaca que corresponde a los Estados alentar el reconocimiento de los niños pequeños como agentes sociales desde el inicio de su existencia, dotados de intereses, capacidades y vulnerabilidades particulares, así como de sus necesidades en materia de protección, orientación y apoyo en el ejercicio de sus derechos.

Por tanto, no visibilizar al niño pequeño es una vulneración de su condición de sujeto de derecho, más aún si se tiene en cuenta que diversos estudios han demostrado que incluso desde la gestación el feto percibe todo lo que acontece a su alrededor, lo cual se fortalece y desarrolla con el nacimiento. De allí que se incida en que los Estados deben garantizar el ejercicio del derecho de todo niño "que esté en condiciones de formarse un juicio propio a emitir opinión", lo que significa que se debe evaluar la capacidad del niño para expresar por el medio que elija una opinión autónoma; la Observación General N. ${ }^{\circ} 12$ hace énfasis en que la capacidad del niño a expresarse se presume, no correspondiendo al niño probar dicha capacidad.

A nivel nacional, resulta importante el reconocimiento del derecho del niño a emitir opinión en diversas normas como en la Ley N. ${ }^{\circ} 30466$, Ley que establece parámetros y garantías procesales para la consideración primordial del interés superior del niño ${ }^{5}$, el Reglamento de la Ley $\mathrm{N}^{\circ}$ 30364 , Ley para prevenir, sancionar y erradicar la violencia contra las mujeres y los integrantes del núcleo familiar, aprobado por Decreto Supremo N. ${ }^{\circ}$ 009-2016-MIMP ${ }^{6}$ y el Decreto Legislativo N. ${ }^{\circ} 1297$, Protección de Niñas, Niños y Adolescentes sin cuidados parentales o en riesgo de perderlos ${ }^{7}$.

Consideramos importante, en lo que al tema respecta, trascribir la apreciación del Tribunal Constitucional Peruano al resolver el Exp. $N^{\circ} 02744$ 2015-PA/TC MADRE DE DIOS:

>> 33. "“(...) en la valoración que formulen las entidades públicas o privadas del interés superior del niño que justificaría la separación de sus padres, tutores $u$ otros responsables, resulta de vital importancia que tomen en cuenta la participación del menor y la manifestación de su opinión, en tanto se trata de medidas que involucran sus propios derechos y cuya decisión es relevante para su vida futura.
“(...) De esta vinculación a dicho principio, se desprende el reconocimiento del derecho de los menores a expresar su opinión y que esta sea tomada en cuenta al momento de adoptar decisiones que incidan en sus derechos. Así, el artículo 12 establece que:

1. Los Estados Partes garantizarán al niño que esté en condiciones de formarse un juicio propio el derecho de expresar su opinión libremente en todos los asuntos que afectan al niño, teniéndose debidamente en cuenta las opiniones del niño, en función de la edad y madurez del niño.

2. Con tal fin, se dará en particular al niño oportunidad de ser escuchado, en todo procedimiento judicial o administrativo que afecte al niño, ya sea directamente o por medio de un representante o de un órgano apropiado, en consonancia con las normas de procedimiento de la ley nacional.

Criterio que también ha sido acogido por la Corte IDH, en su Opinión Consultiva 17/2002, de 28 de agosto de 2002, donde entendió que:

102. En definitiva, el aplicador del derecho, sea en el ámbito administrativo, en el judicial, deberá tomar en consideración las condiciones específicas del 
menor y su interés superior para acordar la participación de éste, según corresponda, en la determinación de sus derechos. En esta ponderación se procurará el mayor acceso del menor, en la medida de lo posible, al examen de su propio caso.

>> $36 .{ }^{\circ}$ Así las cosas, cualquier decisión relativa a la separación del niño respecto de sus padres o de su familia que, a partir del Estado, se adopte a través de sus representantes (funcionarios, autoridades, empleados, etc.), por motivos vinculados con la condición migratoria de uno o ambos progenitores, debe ser excepcional, de carácter temporal, y deberá estar justificada en el interés superior del niño. Una adecuada valoración de este principio deberá tener en cuenta las circunstancias particulares de los padres o familiares del menor en cada caso (historia inmigratoria, lapso temporal de la estadía, la extensión de los lazos del progenitor y/o de su familia con el país receptor, el alcance de la afectación que genera la ruptura familiar debido a la expulsión, entre otros), así como la participación del menor y la manifestación de su opinión, en la medida que se trata de medidas que involucran sus propios derechos y cuya decisión es relevante para su vida futura.

Ello se condice con la configuración del interés superior del niño como la base o fundamento de la doctrina de la protección integral, la cual constituye una superación de las concepciones paterno-autoritarias, al dejar de considerar al niño y el adolescente como objeto de protección, para asumirlos como sujetos a los que es preciso garantizar la satisfacción integral de sus derechos [STC 3247-2008- PHC/ TC]. Este principio orienta la interpretación y entendimiento de los diversos derechos del niño y el adolescente [STC 01817-2009-PHC/ $T C "]$.

Como es de colegir, el máximo intérprete de la Constitución resalta la obligación del Estado, y, por tanto de las autoridades judiciales y administrativas, de recabar y tener en cuenta la opinión del niño en todo momento y que ésta sea valorada debidamente en la decisión, más aún si el hecho a resolver está ligado a la separación provisional o definitiva de los padres, como acontece en los procedimientos de adopción que analizaremos a continuación.

\section{LA ADOPCIÓN COMO CATEGO- RÍA DE LA FILIACIÓN:}

La adopción es una categoría de filiación establecida por la ley que determina el surgimiento de vínculos paterno y materno filiales entre quienes carecen de ellos, generando deberes y derechos recíprocos.

El artículo $115 .^{\circ}$ del Código de los Niños y Adolescentes establece lo siguiente:
>> La Adopción es una medida de protección al niño y al adolescente por la cual, bajo la vigilancia del Estado, se establece de manera irrevocable la relación paterno-filial entre personas que no la tienen por naturaleza. En consecuencia, el adoptado adquiere la calidad de hijo del adoptante y deja de pertenecer a su familia consanguínea.

Por la adopción, los adoptantes asumen los roles parentales del adoptado, sin distingo alguno. En el país la adopción, judicial o administrativa, es plena, pues el adoptado se desvincula totalmente de su familia biológica, para asumir los datos filiatorios de sus adoptantes, en calidad de hijo. Ello implica que adoptantes y adoptado adquieren los mismos derechos y deberes que surgen del parentesco por consaguinidad. Los vínculos jurídicos con la familia de origen desaparecen, los que solo se tendrán presente para efectos de los impedimentos matrimoniales.

Los aspectos más relevantes en materia de adopción son los siguientes:

- La adopción se tramita con arreglo a lo dispuesto en el Código de los Niños y Adolescentes, en la Ley para la protección de niñas, niños y adolescentes sin cuidados parentales 0 en riesgo de perderlos y su reglamento y en Ley de Competencia Notarial, según corresponda ${ }^{8}$.

Conforme a la modificación prevista por la Segunda Disposición Complementaria Modificatoria del Decreto Legislativo $\mathrm{N}^{\circ} 1297$. 
- Terminado el procedimiento, el Juez, el funcionario competente, o el notario que tramitó la adopción, oficiará a los Registros Civiles del Registro Nacional de Identificación y Estado Civil - RENIEC, para que extienda la partida de nacimiento correspondiente, sustituyendo la original y anotando la adopción al margen de la misma para proceder a su archivamiento.

En la nueva partida de nacimiento se consignará como declarantes a los padres adoptantes. Está prohibida toda mención respecto de la adopción, bajo responsabilidad del registrador. La partida original conserva vigencia sólo para el efecto de los impedimentos matrimoniales.

- La adopción es irrevocable y no puede realizarse bajo modalidad alguna.

- Nadie puede ser adoptado por más de una persona, a no ser por los cónyuges o por los convivientes conforme a lo señalado en el artículo $326 .^{\circ}$ del mismo cuerpo normativo.

- El niño o el mayor incapaz que haya sido adoptado puede pedir que se deje sin efecto la adopción dentro del año siguiente a su mayoría o a la fecha en que desapareció su incapacidad. El juez lo declarará sin más trámite. En tal caso, recuperan vigencia, sin efecto retroactivo, la filiación consanguínea y la partida correspondiente. El registro del estado civil res- pectivo hará la inscripción del caso por mandato judicial.

En la legislación comparada9, se regula, además, la adopción "semiplena" según la cual el adoptado conserva su filiación original, trasladándose únicamente al o los adoptantes el ejercicio de la patria potestad y la tenencia del adoptado, lo cual puede revertir nuevamente a favor de los padres biológicos en supuestos expresamente previstos por ley.

Entre las posibles supuestos se comprenden los siguientes: la muerte de los adoptantes, la solicitud del adoptado una vez alcanzada la mayoría de edad o en supuestos de pérdida del ejercicio de la patria potestad por causas específicas.

En relación a la adopción, es importante tener en cuenta que el Estado peruano, mediante Resolución Legislativa $N^{\circ} 26474$, de fecha 01 de junio de 1995, aprobó la "Convención relativa a la Protección del Niño y a la Cooperación en Materia de Adopción Internacional", que, entre otros, reconoce que la adopción internacional puede presentar la ventaja de dar una familia permanente a un niño que no puede encontrar una familia adecuada en su Estado de origen.

Dicho instrumento internacional establece determinadas condiciones para la procedencia de la adopción internacional:

a) Que, se haya establecido que el niño es adoptable; b) Que, se haya constatado, después de haber examinado adecuadamente las posibilidades de colocación del niño en su Estado de origen, que una adopción internacional responde al interés superior del niño;

c) Que, se haya asegurado que:

1. Las personas, instituciones y autoridades cuyo consentimiento se requiera para la adopción han sido convenientemente asesoradas y debidamente informadas de las consecuencias de su consentimiento, en particular en relación al mantenimiento o ruptura en virtud de la adopción, de los vínculos jurídicos entre el niño y su familia de origen,

2. Tales personas, instituciones y autoridades han dado su consentimiento libremente, en la forma legalmente prevista y que este consentimiento ha sido dado o constatado por escrito,

3. Los consentimientos no se han obtenido mediante pago o compensación de clase alguna y que tales consentimientos no han sido revocados, $y$,

4. El consentimiento de la madre, cuando sea exigido, se ha dado únicamente después del nacimiento del niño; $y$,

d) Que, se haya asegurado, teniendo en cuenta la edad y el grado de madurez del niño, lo siguiente:

9 Argentina, Brasil, México, República Dominicana, Francia, Portugal, Polonia, entre otros. 
1. El niño ha sido convenientemente asesorado $y$ debidamente informado sobre las consecuencias de la adopción y de su consentimiento a la adopción, cuando este sea necesario,

2. Se han tomado en consideración los deseos y opiniones del niño,

3. El consentimiento del niño a la adopción, cuando sea necesario, ha sido dado libremente, en la forma legalmente prevista y que este consentimiento ha sido dado o constatado por escrito, $y$,

4. El consentimiento no ha sido obtenido mediante pago o compensación de clase alguna.

Es importante resaltar, que este instrumento internacional, incide en 02 aspectos de suma importancia para dar trámite a la adopción internacional, como son: 1) que, responda al interés superior del niño; y, 2) que, el niño preste su consentimiento, lo cual es una realización del derecho del niño a emitir opinión.

Estas exigencias se sustentan en el reconocimiento del niño como sujeto de derechos y en los principios rectores de la doctrina de protección integral: el interés superior del niño y el reconocimiento de su derecho de opinión.

De otro lado, conviene destacar que el Código de los $\mathrm{Ni}$ ños y Adolescentes regula la adopción de dos formas:

\section{1) POR DEMANDA ANTE EL} JUEZ ESPECIALIZADO:

En caso se invoque alguno de los supuestos siguientes:

a) Vínculo matrimonial con el padre o madre del niño por adoptar.

b) Vínculo de parentesco hasta el cuarto grado de consanguinidad o segundo de afinidad con el niño por adoptar; y

c) Prohijamiento o convivencia con el niño durante un período no menor de dos años.

En cualquiera caso, la acción procede sin necesidad de declaración previa del estado de abandono, pues se entiende que el niño no se encuentra inmerso en ninguno de los casos previstos por el artículo $248 .^{\circ}$ del Código de los Niños y Adolescentes, sino, que la intención es regularizar los lazos afectivos paterno o materno filiales que de hecho han surgido como resultado de la convivencia con el niño, niña o adolescente.

De allí que la opinión y sentir del niño es preponderante en la decisión judicial, aunado al deber del Juez, en despliegue de su rol tuitivo, de verificar que la pretensión satisfaga plenamente el interés superior del niño por adoptar .

Es relevante mencionar, que el artículo $128 .^{\circ}$ del Código de los Niños y Adolescentes que regula la adopción por excepción, a la cual nos hemos referido en forma precedente, ha sido modificado por la Primera Disposición Complementaria Modificatoria del Decreto Legislativo $\mathrm{N}^{\circ}$ 1297, publicado el $30 \mathrm{di}$ ciembre del año $2016^{10}$, de tal forma que solo se mantienen los supuestos a) y b) precitados. Eliminándose el inherente al prohijamiento o convivencia con el niño.

\section{2) POR PROCEDIMIENTO ADMINISTRATIVO:}

El artículo $119 .^{\circ}$ del Código de los Niños y Adolescentes, modificado por la Primera Disposición Complementaria Modificatoria del Decreto Legislativo $N^{\circ} 1297$, confiere la titularidad del procedimiento de adopciones al Ministerio de la Mujer y Poblaciones Vulnerables, reconociéndola como la institución encargada de tramitar las solicitudes de Adopción de niños o de adolescentes declarados en "desprotección familiar y adoptabilidad", con las excepciones señaladas en el artículo 128 del presente Código.

Antes de la modificación normativa, la autoridad administrativa asumía competencia en estos procedimientos en caso de niños, niñas y adolescentesdeclarados previamente en "estado de abandono", esto es, al haberse constatado que se encontraban inmersos en alguno de los supuestos del artículo $248 .^{\circ}$

10 Entrará en vigencia a partir del día siguiente de la publicación de su reglamento. 
del Código de los Niños y Adolescentes ${ }^{11}$.

La investigación recaía en la autoridad administrativa, en tanto que la declaración del estado de abandono correspondía exclusivamente a la autoridad jurisdiccional, previo dictamen fiscal.

Acorde al Decreto Legislativo N. ${ }^{\circ} 1297$, se derogan, entre otros, los artículos $243 .^{\circ}$, $244 .^{\circ}, 245 .^{\circ}, 246 .^{\circ}, 247 .^{\circ}$, $248 .^{\circ}, 249 .^{\circ}, 250 .^{\circ}, 251 .^{\circ} \mathrm{y}$ 252. ${ }^{\circ}$ del Código de los $\mathrm{Ni}$ ños y Adolescentes ${ }^{12}$, la Ley N. ${ }^{\circ}$ 30162, Ley de Acogimiento Familiar, la Ley $\mathrm{N}^{\circ} 29174$, Ley General de Centros de Atención Residencial de Niñas, Niños y Adolescentes, los artículos 1, 2, 3, 4, Tercera y Cuarta Disposición Final de la Ley $N .^{\circ} 28190$, Ley que Protege a los Menores de Edad de la Mendicidad, el artículo 511. ${ }^{\circ}$ del Código Civil sobre tutela de niños, niñas y adolescentes en desprotección familiar y la Ley N. ${ }^{\circ} 26981$, Ley del Procedimiento Administrativo de Adopción de Menores de Edad Declarados Judicialmente en Abandono $^{13}$ (Ley $N^{\circ}$ 26981).
La norma regula la "desprotección familiar" como manifestación del incumplimiento o inadecuado desempeño de los deberes de cuidado y protección a un niño, hecho que afecta gravemente su desarrollo integral. Así, el artículo $1 .^{\circ}$ de la norma en referencia prevé que la finalidad del procedimiento es la protección integral de las niñas, niños y adolescentes a fin de garantizarles el pleno ejercicio de todos sus derechos, sobretodo el vivir, crecer y desarrollarse en el seno de su familia.

En ese sentido, el literal g) del artículo $3 .^{\circ}$ establece que la situación de "desprotección familiar" tiene carácter provisional e implica la separación temporal de la niña, niño o adolescente de su familia para su protección, así como el apoyo especializado a la familia para la remoción de las circunstancias que la motivaron; sin embargo, el artículo 92. ${ }^{\circ}$ regula la potestad de la autoridad administrativa de promover la respectiva "declaración judicial de desprotección familiar" cuando del seguimiento y evaluación del plan de trabajo individual se determine que no existe posibilidad de reintegración del niño a su entorno familiar o resulte contrario a su interés superior.

La decisión administrativa debe tomar en cuenta la opinión del niño y sustentarse tanto en su interés superior como en los principios de necesidad e idoneidad. Ello resulta positivo, pues se materializa en la práctica las Observaciones Generales del Comité de los Derechos del Niño N. ${ }^{\circ} 12$ (2009) y 14 (2013), respectivamente ${ }^{14}$.

Los supuestos que pueden dar lugar a la declaración de desprotección familiar deben ser desarrollados por el Reglamento; no obstante, en ningún caso la pobreza ni la discapacidad del niño o de alguno de los miembros de su entorno familiar justifica por sí misma la separación del niño de su entorno familiar, lo cual también es relevante, pues resulta coherente con el reconocimiento del derecho del niño de desarrollarse en el seno de su propia familia, conforme así se destaca en el Preámbulo de

11 Artículo 248. - Casos. -

El Juez especializado podrá declarar en estado de abandono a un niño o adolescente cuando: a) Sea expósito; b) Carezca, en forma definitiva, de las personas que conforme a la ley tienen el cuidado personal de su crianza, educación o, si los hubiera, incumplan las obligaciones o deberes correspondientes; o carecieran de las calidades morales o mentales necesarias para asegurar la correcta formación; c) Sea objeto de maltratos por quienes están obligados a protegerlos o permitir que otros lo hicieran; d) Sea entregado por sus padres a un establecimiento de asistencia social público o privado y lo hubieran desatendido injustificadamente por seis meses continuos o cuando la duración sumada exceda de este plazo; e) Sea dejado en instituciones hospitalarias u otras similares con el evidente propósito de abandonarlo; f) Haya sido entregado por sus padres o responsables a instituciones públicas o privadas, para ser promovido en adopción; g) Sea explotado en cualquier forma o utilizado en actividades contrarias a la ley o a las buenas costumbres por sus padres o responsables, cuando tales actividades sean ejecutadas en su presencia. h) Sea entregado por sus padres o responsables a otra persona mediante remuneración o sin ella con el propósito de ser obligado a realizar trabajos no acordes con su edad; y i) Se encuentre en total desamparo. La falta o carencia de recursos materiales en ningún caso da lugar a la declaración del estado de abandono.

12 Referentes a las medidas de protección al niño y adolescente en presunto estado de abandono y declaración judicial del estado de abandono.

13 Razón por la cual el Reglamento de la Ley N. 26981 (aprobado por Decreto Supremo N. ${ }^{\circ}$ 010-2005.MIMDES) y la Directiva General N. ${ }^{\circ}$ 002-2016-MIMP, que establece los "Lineamientos de Evaluación Integral para la Adopción de Niños, Niñas y Adolescentes Declarados Judicialmente en Abandono, deben igualmente ser derogados.

14 El derecho del niño a ser escuchado y el derecho del niño a que su interés superior sea una consideración primordial. 
la Convención sobre los Derechos del Niño.

La Convención sobre los Derechos del Niño por el artículo $3 .^{\circ}$, además de consagrar en su primer párrafo el "Principio del Interés Superior del Niño", inmediatamente subraya la obligación que tienen los Estados de asegurarles protección y cuidado, teniendo en cuenta los derechos y deberes de los padres, tutores u otros responsables, de tal forma que el niño no debe ser separado de sus padres, salvo que dicha medida se sustente en garantizar su bienestar, como sucedería en supuestos de maltrato, descuido, perjuicio, abuso, descuido, trato negligente, explotación, etc.

En situaciones como las descritas se justifica la intervención estatal mediante acciones administrativas y judiciales adecuadas que garanticen la protección del niño, conforme lo dispuesto por los artículos $9 .^{\circ}, 19 .^{\circ}$ y $20 .^{\circ}$ de la Convención ${ }^{15}$, lo cual entendemos sustentan los alcances del Decreto Legislativo $\mathrm{N} .{ }^{\circ}$ 1297.

Los literales () y m) del artículo $3 .^{\circ}$ de la citada norma, desarrollan las siguientes definiciones:

\section{l) Adoptabilidad}

Es la condición que adquiere la niña, niño o adolescente declarado en desprotección familiar, al haberse determinado, mediante una evaluación psicosocial, que la adopción es la medida de protección más idónea para garantizar el desarrollo integral de la niña, niño o adolescente.

\section{m) Adopción}

Es una medida de protec-
ción e integración familiar,
de carácter definitivo,
garantista y excepcional,
que tiene por objeto hacer

15 Artículo 9

1.Los Estados Partes velarán por que el niño no sea separado de sus padres contra la voluntad de éstos, excepto cuando, a reserva de revisión judicial, las autoridades competentes determinen, de conformidad con la ley y los procedimientos aplicables, que tal separación es necesaria en el interés superior del niño. Tal determinación puede ser necesaria en casos particulares, por ejemplo, en los casos en que el niño sea objeto de maltrato o descuido por parte de sus padres o cuando éstos viven separados y debe adoptarse una decisión acerca del lugar de residencia del niño.

2.En cualquier procedimiento entablado de conformidad con el párrafo 1 del presente artículo, se ofrecerá a todas las partes interesadas la oportunidad de participar en él y de dar a conocer sus opiniones.

3.Los Estados Partes respetarán el derecho del niño que esté separado de uno o de ambos padres a mantener relaciones personales y contacto directo con ambos padres de modo regular, salvo si ello es contrario al interés superior del niño.

4.Cuando esa separación sea resultado de una medida adoptada por un Estado Parte, como la detención, el encarcelamiento, el exilio, la deportación o la muerte (incluido el fallecimiento debido a cualquier causa mientras la persona esté bajo la custodia del Estado) de uno de los padres del niño, o de ambos, o del niño, el Estado Parte proporcionará, cuando se le pida, a los padres, al niño o, si procede, a otro familiar, información básica acerca del paradero del familiar o familiares ausentes, a no ser que ello resultase perjudicial para el bienestar del niño. Los Estados Partes se cerciorarán, además, de que la presentación de tal petición no entrañe por sí misma consecuencias desfavorables para la persona o personas interesadas.

Artículo 19

1.Los Estados Partes adoptarán todas las medidas legislativas, administrativas, sociales y educativas apropiadas para proteger al niño contra toda forma de perjuicio o abuso físico o mental, descuido o trato negligente, malos tratos o explotación, incluido el abuso sexual, mientras el niño se encuentre bajo la custodia de los padres, de un representante legal o de cualquier otra persona que lo tenga a su cargo.

2.Esas medidas de protección deberían comprender, según corresponda, procedimientos eficaces para el establecimiento de programas sociales con objeto de proporcionar la asistencia necesaria al niño y a quienes cuidan de él, así como para otras formas de prevención y para la identificación, notificación, remisión a una institución, investigación, tratamiento y observación ulterior de los casos antes descritos de malos tratos al niño y, según corresponda, la intervención judicial.

\section{Artículo 20}

1.Los niños temporal o permanentemente privados de su medio familiar, o cuyo superior interés exija que no permanezcan en ese medio, tendrán derecho a la protección y asistencia especiales del Estado.

2.Los Estados Partes garantizarán, de conformidad con sus leyes nacionales, otros tipos de cuidado para esos niños. 3.Entre esos cuidados figurarán, entre otras cosas, la colocación en hogares de guarda, la kafala del derecho islámico, la adopción o de ser necesario, la colocación en instituciones adecuadas de protección de menores. Al considerar las soluciones, se prestará particular atención a la conveniencia de que haya continuidad en la educación del niño y a su origen étnico, religioso, cultural y lingüístico. 
efectivo el derecho a vivir en familia de la niña, niño o adolescente declarado en estado de desprotección familiar y con estado de adoptabilidad.

Es oportuno rememorar, que el Ministerio de la Mujer y Poblaciones Vulnerables en el año 2013 expidió la Directiva General N 004-2013-MIMP, que delimita las "Normas y lineamientos para la promoción de la adopción prioritaria de niños, niñas y adolescentes por designación directa", siendo los beneficiados aquellos que hubieran sido declarados judicialmente en estado de abandono o desprotección familiar en atención a que tienen más de 09 años de edad, presentan alguna discapacidad o problema de salud o se trata de grupos de hermanos.

La intención administrativa es garantizar a los niños comprendidos en las categorías precitadas, ejercer su derecho fundamental a la no discriminación y a vivir, crecer y desarrollarse en el seno de una familia, más aún el deseo de los peticionantes de atender las necesidades afectivas, emocionales y de toda índole de un grupo de niños que por sus características personales en más de un caso son marginados por la sociedad, lo cual responde al deber prioritario del Estado y la comunidad de protección de todos los niños sin excepción como así se consagra en el artículo $4 .^{\circ}$ de la Norma Fundamental ${ }^{16}$.
El artículo $116 .^{\circ}$ del Código de los Niños y Adolescente regula la subsidiariedad de la adopción por extranjeros respecto de la adopción tramitada por nacionales y la preferencia de ésta última en caso de concurrir solicitudes de nacionales y extranjeros.

El legislador por medio de ésta norma privilegia dos aspectos importantes a resaltar: de un lado, el derecho del niño a gozar de una familia con características y costumbres similares a las suyas, y, de otro, el trato preferente que merece el connacional respecto de similar solicitud de adopción de un extranjero.

En correspondencia a lo primero, consideramos que la previsión legal satisface la consideración prioritaria que merece de parte del Estado el interés superior del niño, pues con la preferencia por la adopción a favor de adoptantes nacionales se le brinda al niño la oportunidad de crecer y desarrollarse en el país en el que se encuentran sus orígenes.

Respecto de lo segundo, resulta obvio que la adopción a favor de un peticionante peruano permite en mayor grado el seguimiento post adoptivo, para efectos de verificar que la adopción ha sido favorable a los intereses del adoptado, esto es, que los adoptantes cumplen a cabalidad las responsabilidades parentales derivadas de la adopción.
La adopción a favor de extranjeros exige como requisitos los siguientes:

- Solo pueden adoptar en el Perú aquellas personas cuyo país de residencia o los Organismos Acreditados y autorizados, hayan suscrito Tratado o Convenio en la materia con el Perú o con la Dirección General de Adopciones el que deberá encontrarse vigentes.

- Los adoptantes residentes en el extranjero deberán presentar su solicitud de adopción a los centros o instituciones autorizados por su país de residencia para tramitar adopciones internacionales de conformidad con los convenios internacionales vigentes.

- Para tal efecto los adoptantes deberán acudir a la autoridad central extranjera competente y presentar su documentación a través de esta entidad o de aquella institución que la autoridad central autorice expresamente. Los documentos exigidos por la legislación peruana son:

- Solicitud dirigida a la Dirección General de Adopciones en la que se presenta él o los solicitantes exponiendo su motivo para adoptar una niña, niño 0 adolescente.s

\section{- Copia legalizada del pasaporte}

16 Protección a la familia. Promoción del matrimonio

Artículo 4. - La comunidad y el Estado protegen especialmente al niño, al adolescente, a la madre y al anciano en situación de abandono. También protegen a la familia y promueven el matrimonio. Reconocen a estos últimos como institutos naturales y fundamentales de la sociedad.

La forma del matrimonio y las causas de separación y de disolución son reguladas por la ley. 
- Autorización oficial de su país para adoptar una niña, niño o adolescente peruano en estado de abandono judicialmente declarado.

- Partida de nacimiento de los adoptantes.

- Partida de matrimonio civil, de ser el caso.

- En caso de ser divorciado o divorciada, copia certificada de la sentencia de divorcio o documento equivalente.

- Partida de nacimiento del hijo/a o hijos/as biológicos/as, de ser el caso.

- En caso de viudez, partida de defunción correspondiente.

- En caso de tener hijo/a o hijo/as adoptados/as, presentar sus partidas de nacimiento y reportes de seguimiento post adoptivo, en aquellas adopciones que no hayan sido tramitadas a través de la Secretaría Nacional de Adopciones.

- Certificados negativos de antecedentes policiales y penales.

- Certificado o documento que acredite el no ser deudor alimentario moroso o en su defecto una declaración jurada.

- Certificado domiciliario o documento equivalente.

- Certificados médicos de salud física y mental, con una antigüedad no mayor de 3 meses, expedidos por un centro de salud o institución autorizada, incluyendo los resultados de los exámenes de HIV Hepatitis $B$, otras enfermedades infecto-contagiosas y rayos $X$ de pulmones del o los adoptantes y de las personas que convivan con ellos.

- Certificados de trabajo, constancia de ingresos, declaración jurada del impuesto a la renta y demás documentos que acrediten ingresos estable y capacidad económica.

- Fotografía de los adoptantes, de los interiores, exteriores del hogar y de sus familiares en hoja A-4 Bond, con una antigüedad no mayor a 4 meses.

- Informe psico-social de los adoptantes, el que deberá contener la motivación para adoptar, relaciones intrafamiliares, relaciones sociales y relaciones interpersonales, evaluación de su situación económica, así como cualquier otro aspecto que permita una mayor aproximación a su entorno socio-familiar el que deberá estar firmado por un psicólogo titulado y un trabajador social titulado.

- Compromiso de seguimiento post-adoptivo expedido por la autoridad central del país de residencia de los adoptantes consistente en la remisión de informes semestrales del niño adoptado por un período de 4 años.
- Toda la documentación presentada por los adoptantes residentes en el exterior deberá estar debidamente legalizada por las autoridades oficiales del país extranjero, por el Consulado Peruano y por el Ministerio de Relaciones Exteriores del Perú; y en caso de estar en otro idioma deberá estar traducida al español por traductor publico cuya firma también deberá estar legalizada en caso de ser extranjero y debe ser remitida debidamente ordenada en dos fólders plastificados para adjuntar los originales y las copias por separado.

- La presencia de los solicitantes no es necesaria sino hasta el momento que la Dirección General de Adopciones les comunique que han sido designados como adoptantes de un niño, niña o adolescente.

- Asimismo, se les informa que no se requiere de la firma ni asesoría legal de abogado; el trámite es gratuito, cualquier duda o consulta gustosamente será absuelta por cualquiera de los profesionales que laboran en la Dirección General de Adopciones.

Es importante resaltar que el artículo $118 .^{\circ}$ del Código de los Niños y Adolescentes prevé que "si ocurrieren circunstancias imprevistas que impidan culminar el trámite de adopción, la Oficina de Adopciones adoptará las medidas pertinentes teniendo en cuenta el Interés Superior del Niño y del Adolescente". 
Por "circunstancias imprevistas" se puede inferir cualquier hecho que surge en pleno procedimiento de adopción y que por su trascendencia impide su culminación. Entre dichos sucesos podríamos identificar la muerte de los adoptantes, una enfermedad grave, privación de la libertad o la iniciación de procesos penales contra los adoptantes que impliquen situación de riesgo para el niño o el no deseo de los propios adoptantes de continuar con el procedimiento.

En cualquier caso, corresponderá a la autoridad administrativa adoptar inmediatamente las medidas de protección que resulten pertinentes con la finalidad de garantizar el desarrollo holístico del niño, entendiéndose por ello favorecer su crecimiento físico, mental, espiritual, moral, psicológico y social.

De tal forma, que al haberse frustrado las expectativas de una adopción, corresponderá posibilitar un nuevo procedimiento; entre tanto, se deberá asegurar al niño la posibilidad de desenvolverse en una familia, pues la institucionalización siempre debe ser una medida de última ratio y por el menor tiempo posible.
Es interesante mencionar que el Decreto Legislativo N. ${ }^{\circ} 1297$ contempla como principios específicos del procedimiento de adopción los referentes a la idoneidad de la familia adopta nte, la preservación de los vínculos fraternos y el carácter subsidiario de la adopción internacional, además de los previstos por el artículo $4 .^{\circ} \mathrm{de}$ la propia norma ${ }^{17}$.

Acorde al principio de "idoneidad de la familia adoptante", la decisión de promover en adopción a una niño debe garantizar que la familia elegida sea la más apropiada para satisfacer sus necesida-

17 Artículo 4.- Principios de la actuación protectora

La actuación estatal frente a las situaciones de riesgo o desprotección familiar se rige principalmente por los siguientes principios:

a) Diligencia excepcional

La actuación del Estado frente a situaciones de riesgo o desprotección familiar exige la mayor celeridad, cuidado, eficacia y responsabilidad por parte de los órganos y funcionarios competentes en todas las acciones y decisiones que adopten en garantía de los derechos de los niños, niñas y adolescentes. Este principio es especialmente relevante en el análisis de las circunstancias que rodean y afectan a la niña, niño o adolescente, la valoración objetiva del impacto de las mismas en sus derechos, la justificación de las decisiones y su revisión oportuna.

b) Especialidad y profesionalización

La actuación estatal es planificada y se realiza a través de profesionales y técnicos debidamente especializados. La capacitación es periódica.

c) Excepcionalidad y temporalidad

La adopción de una medida de protección que implique la separación de la niña, niño o adolescente de su familia de origen es excepcional y por el más breve plazo, que debe sustentarse en la existencia de circunstancias objetivas y en función al Interés Superior del Niño.

d) Igualdad y no discriminación

Todas las niñas, niños o adolescentes que se encuentren dentro del territorio nacional, tienen derecho a la protección del Estado ante situaciones de riesgo o de desprotección familiar, sin discriminación alguna por motivos de raza, sexo, género, color de piel, idioma, religión, nacionalidad, origen étnico o social, discapacidad o cualquier otra condición de la niña, niño, adolescente o de su madre, padre, tutora o tutor o familia de origen.

e) Informalismo

Las normas que regulan los procedimientos por riesgo o desprotección familiar, deben ser interpretadas, de modo que los derechos e intereses de las niñas, niños y adolescentes, de su madre, padre, familia extensa o de origen, tutora o tutor, no sean afectados por la exigencia de aspectos formales que puedan ser subsanados dentro del procedimiento, siempre que dicha excusa no afecte derechos de terceros.

f) Integración familiar

La actuación del Estado debe promover de manera prioritaria la integración de la niña, niño o adolescente en su familia de origen, realizando las acciones necesarias para este fin.

g) Interés Superior del Niño

Este derecho sustancial, principio de interpretación y norma de procedimiento, asegura la protección y desarrollo integral de la niña, niño o adolescente en su familia y en caso excepcional, prioriza un entorno familiar alternativo. A fin de determinar el interés superior del niño, se respetan los vínculos familiares y se favorece el apoyo a la familia de origen como medida de protección prioritaria. En ningún caso su aplicación puede disminuir o restringir los derechos y garantías reconocidos a las niñas, niños y adolescentes.

Cuando exista conflicto entre el interés superior de un niño y otros intereses o derechos, la autoridad competente analiza y pondera los derechos de todos los interesados, teniendo en cuenta que el derecho de la niña, niño y adolescente a que su interés superior es una consideración primordial. 
des específicas, circunstancias e interés superior; por tanto, en caso de constatarse que los adoptantes por diversas causas no son idóneos para garantizar el desarrollo holístico del niño, el procedimiento de adopción debe suspenderse.
En suma, en todo proceso o procedimiento de adopción, los niños en general deben tener garantizado el ejercicio pleno de sus derechos a la defensa, conocer sus orígenes, conservar su prenombre (salvo que sea contrario a sus intereses) y nacionalidad, parti- cipar en todo el procedimiento de adopción, entre otros, así como emitir, sin restricción alguna, su opinión, deseo y sentir respecto de la adopción en sí misma y que ésta opinión sea tenida en cuenta y valorada por la autoridad llamada a resolver el caso.

h) Flexibilidad y gradualidad

Las medidas de protección dictadas a favor de una niña, niño o adolescente deben adecuarse a la variación de sus circunstancias personales y familiares, por lo que deben ser periódicamente revisadas.

i) Necesidad e idoneidad

El principio de necesidad implica que la separación de la niña, niño o adolescente de su familia, sea dispuesta únicamente cuando todos los medios posibles para mantenerlo en su familia, no han surtido efecto o han sido descartados. El principio de idoneidad implica la selección de la medida de protección más adecuada y que mejor satisfaga las necesidades de cada niña, niño o adolescente.

j) Subsidiaridad progresiva de la actuación del Estado

Cuando la familia de origen tenga dificultades para cumplir sus obligaciones de cuidado y protección, el alcance y la intensidad de la actuación estatal para garantizar los derechos de la niña, niño o adolescente, es proporcional al grado de riesgo o desprotección familiar en la que se encuentre.

k) Interculturalidad

El Estado y la sociedad valoran e incorporan las diferentes visiones culturales, concepciones de bienestar y desarrollo de los diversos grupos étnicos-culturales del país al que pertenecen las niñas, niños y adolescentes, para garantizar el ejercicio de sus derechos. 